\title{
Valuating the Investment Efficiency of Distribution Companies
}

\begin{abstract}
M. Karajica
The task of this study is to valuate the investment efficiency of distribution companies. Although a series of publications and studies has been dedicated to this topic, it is difficult to find a general consensus in defining the investment efficiency of a company. Nevertheless if we simplify an imaginary company as a production unit in which a series of actions transforms inputs to outputs, efficiency can be understood as like an effort to achieve maximum value of the outputs together with minimum usage of inputs, where the inputs constitute investments by a company. The investment efficiency of a company can be measured by expressing the absolute values of selected inputs and outputs, a relative expression of inputs and outputs, and perhaps an expression of the difference between them. However, an examination of the efficiency of a certain company is impossible without a valuation of other companies. In view of the amount of benchmarking, it should be emphasized, that this study is dedicated to a certain category of benchmarking, which we may term investment benchmarking. This benchmarking can be defined as a comparison of companies in terms investment efficiency. The purpose of this comparison is not only to investigate levels of investment efficiency and to relate them to other companies from the same branch, but also to locate the greatest efficiency and indicate potential improvement.
\end{abstract}

Keywords: Benchmarking, investment efficiency, Multi Criteria Decision Making methods, Modified Score Method, Data Analysis Envelopment, returns on scale, CCR model, distribution companies, valuation criteria.

\section{Methodology}

The implementation of investment benchmarking requires methods that are not categorized in the special literature. However, for the purposes of this study it is appropriate to divide the methods applicable for investment benchmarking into one-dimensional and multi-dimensional methods.

The simplest way to established benchmarks is by comparing companies according to only one indicator. Through such a comparison we obtain an ordered set of companies according to the chosen indicator. The question then concerns the benefits or disadvantages of using an absolute or a relative indicator. When we valuate according to an absolute indicator we obtain a concrete conception, expressed in units, about the selected criterion. However, as disadvantage of this classification is the absence of information about the input or about the source of the value of the chosen indicators. This absence removes assessment, according to relative indicators. However, it is also impossible to rely purely on relative indicators. The difficulty with relative indicators rests in the presumption of linearity that may in reality be misleading. A decision on the manner of valuation will be troublesome. Both solutions imply a certain view on the problem under investigation.

Assessing the investment efficiency of a company at a given time using several indicators can be difficult when, that the company achieves different results according to particular indicators. In this case we require methods that can help us to make a total assessment of efficiency. This task can be performed by using multi-dimensional methods. The segmentation of these methods is not generally defined. However, the following methods are applicable for presentation purposes.

\section{- Multi Criteria Decision Making methods, \\ - Data Analysis Envelopment.}

These two methods enable the investment efficiency of companies to be measured through elective indicators that have an influence on the total investment efficiency of a com- pany. Indicators representing efficiency can be of a financial or non-financial character, depending on the branch in which the company operates. It should be emphasized, that Multi Criteria Decision Making methods are common tools for multi-dimensional valuation, while Data Analysis Envelopment is an alternative approach to valuation. The following sections offer a brief description of Multi Criteria Decision Making methods and Data Analysis Envelopment.

\subsection{Multi criteria decision making methods}

A range of Multi Criteria Decision Making (MCDM) methods are presented in the literature. They can be categorized into methods based on: determining the order in the particular criteria, determining the base in the particular criteria, valuating the distance from an imaginary object and geminate comparison Dudorkin [1], Fiala [2].

However, for the purposes of this study it is sufficient to choose a method providing reliable and transparent results. A method that provides the required characteristics is the Modified Score Method (MSM). This method appertains to the set of methods founded on determining the base in the particular criteria, which is usually the most favorable value, the arithmetic mean or the median. All the values of the existing indicator, are related to the selected base, so that methods of this kind provide objective results. Another advantage of these methods is easy interpretation of the results and relatively low demands on calculation. These methods are criticized for giving a positive assessment of companies even for the worst value achieved for a given indicator, which means that the total valuations of the compared companies are not very for apart. The Modified Score Method deals with this problem.

\subsubsection{Modified score method}

The principle of this method, is that, for each indicator we have to find the company for which the appropriate indicator achieves the maximum value (if growth of the indicator is 
desirable) or the minimum value (if a decline of the indicator is desirable). Such company receives 100 points for this indicator by. The other companies will obtain a proportion of the points $b_{i j}$ valuated by the following formula

$b_{i j}=\frac{x_{i j}-x_{j, \min }}{x_{j, \max }-x_{j, \min }} \cdot 100 \quad$ (desirable growth of indicator),

$b_{i j}=\frac{x_{j, \max }-x_{i j}}{x_{j, \max }-x_{j, \min }} \cdot 100 \quad$ (desirable decline of indicator),

where $x_{i j}$ is the value of the $j$-th indicator of the $i$-th company, $x_{j, \max }$ is the highest value of the $j$-th indicator, $x_{j \text {,min }}$ is the lowest value of the $j$-th indicator, while $i=1, \ldots, m$ and $j=1, \ldots, n$. The total investment efficiency valuation is equal to the average value of points awarded $b_{i}$, obtained according to the following formula

$$
b_{i}=\frac{1}{n} \sum_{j=1}^{n} b_{i j}, \quad i=1, \ldots, m .
$$

The total valuation $b_{i}$, when using different weights of the indicators, is given by the weighted average

$$
b_{i}=\frac{\sum_{j=1}^{n} b_{i j} w_{j}}{\sum_{j=1}^{n} w_{j}}, \quad i=1, \ldots, m
$$

The highest attainable value, of the total assessment is 100 points. This value can be understood as the percentage of the achieved investment efficiency of a company as represented by the selected indicators. It is evident that the overall assessment of a given company will reach the limit of 100 points only if the most favorable values have been achieved all indicators. Since case is rare in practice, it is appropriate to normalize the total assessment $b_{i}$ to the interval $0-1$. Normalization is achieved by relating the total assessment bi of the appropriate company toward the most favorable total assessment $b_{i}$ across all compared units. This normalization is denoted below as the relative valuation of the Modified Score Method.

\subsection{Data analysis envelopment}

The minimizing criteria in the Data Analysis Envelopment (DEA) models are denoted as inputs, and the maximizing criteria as outputs. Acknowledged weights of the particular indicators are analogous to multi criteria decision making methods. However, a significant difference between these approaches to valuation is that the weights are not determined by a value-maker but by calculation. In this way, less data is required, and this is an advantage over Multi Criteria Decision Making methods. Data Analysis Envelopment models also have a disadvantage in comparison with Multi Criteria Decision Making methods. This disadvantage is the high demands on calculation and the limited number of elective inputs and outputs depending on the number of units of comparison. No precise relationship between the number of selected criteria and the number of units has been introduced in the literature.
Data Analysis Envelopment includes a range of models varying above all in presumption about returns on scale. Fig. 1 illustrates acceptable types of returns on scale for only one input and output.
Constant Returns to Scale

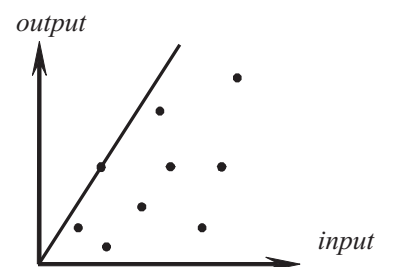

Non-Increasing Returns to Scale

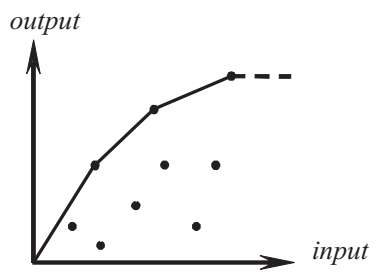

Variable Returns to Scale

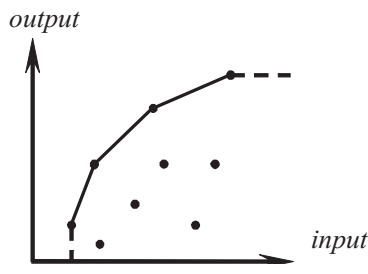

Non-Decreasing Returns to Scale

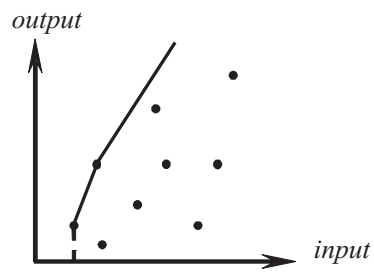

Fig. 1: Shape of the efficiency line for various returns on scale

Fig. 1 for constant returns on scale, shows that only one unit (company) is efficient, as it lies on the efficiency line. In the case of constant returns on scale, this is a straight line from the origin of coordinates with its derivation equal to the highest value of the rate output and input of a particular unit. All units below the efficiency line are ineffective, and their rate of inefficiency is directly proportional to the distance from the line. It is difficult to determine the character of the returns on rate, which depends on a wide range of factors, so this study applies the CCR model of Data Analysis Envelopment, supposing constant returns on scale. The principle and a mathematical description of this model are stated in the following section.

\subsubsection{CCR model}

The first Data Analysis Envelopment model was proposed by Charnes, Cooper and Rhodes [3]. This model is denoted as the CCR model. The efficiency of the units is valuated by the theorem

$E_{k}=\frac{u_{1} y_{1 k}+u_{2} y_{2 k}+\cdots+u_{s} y_{s k}}{v_{1} x_{1 k}+v_{2} x_{2 k}+\cdots+v_{r} x_{r k}}=\frac{\sum_{j=1}^{s} u_{j} y_{j k}}{\sum_{i=1}^{r} v_{i} x_{i k}}, \quad k=1, \ldots, n$,

where $E_{k}$ is efficiency of the $k$-th unit, $x_{i k}$ is $i$-th input of the $k$-th unit, $y_{j k}$ is $j$-th output of the $k$-th unit, $v_{i}$ is weight of the $i$-th input, $u_{j}$ is weight of the $j$-th output, $r$ is number of inputs, and $s$ is number of outputs. For each unit, different values of the weights can be sets. The purpose is to find the optimal set of weights for which a given unit achieves maximum efficiency. The condition of the calculation is that, for a given set of weights, the efficiency value of all the participating units 
must be lower or equal to the upper efficiency limit, which is equal to 1 . The optimal set of weights is calculated for each unit. The mathematical formulation for this exercise is:

$$
\max h_{k_{0}}=\frac{\sum_{j=1}^{s} u_{j} y_{j k_{0}}}{\sum_{i=1}^{r} v_{i} x_{i k_{0}}}
$$

subject to

$$
\begin{array}{ll}
\frac{\sum_{j=1}^{s} u_{j} y_{j k}}{\sum_{i=1}^{r} v_{i} x_{i k}} \leq 1, & \\
u_{j} \geq 0, & j=1, \ldots, k_{0}, \ldots, n, \\
v_{i} \geq 0, & i=1, \ldots, r,
\end{array}
$$

where $h_{k_{0}}$ is efficiency rate of unit $k_{0}, x_{i k}$ is $i$-th input the $k$-th unit, $y_{j k}$ is $j$-th output the $k$-th unit, $v_{i}$ are the weights assigned to the $i$-th input and $u_{j}$ are weights assigned to $j$-th output, while $i=1, \ldots, r, j=1, \ldots, s$ and $k=1, \ldots, k_{0}, \ldots, n$.

For the practical application it is necessary to transform this exercise to a standard linear programming exercise. The exercise is transformed using the Charnes-Cooper transformation, which keeps the weighted sum of the inputs equal to constant). While calculating efficiency of a given unit, maximum efficiency rate could be achieved by entirely rendering some of the inputs or outputs. To prevent this, we have to impose the infinitesimal constant $\varepsilon$, with the help of which we establish the lowest limit of the inputs and outputs weights. The value of constant $\varepsilon$ depends on the values of the applied inputs and outputs with regard to Charnes-Cooper transformation. Supplementing the presented here with this transformation and constant $\varepsilon$, we obtain the primary CCR model oriented on inputs. The model is formulated as follows:

$$
\max z_{k_{0}}=\sum_{j=1}^{s} u_{j} y_{j k_{0}},
$$

subjected to

$$
\begin{gathered}
\sum_{j=1}^{s} u_{j} y_{j k} \leq \sum_{i=1}^{r} v_{i} x_{i k}, \quad k=1, \ldots, k_{0}, \ldots, n, \\
\sum_{i=1}^{r} v_{i} x_{i k_{0}}=1, \\
u_{j} \geq \varepsilon, \quad j=1, \ldots, s, \\
v_{i} \geq \varepsilon, \quad i=1, \ldots, r,
\end{gathered}
$$

where $z_{k_{0}}$ is efficiency of unit $k_{0}$. The description of other symbols are as in the previous model.

\section{Comparative analysis of companies}

The previous section presented a theoretical description of the Multi Criteria Decision Making Method and Data Analysis Envelopment, which provide ways to evaluate the invest- ment efficiency of companies. However, these tools for supporting a valuation of investment efficiency require relevant assessment criteria.

\subsection{Selection of subjects for comparison}

Emphasis was placed on selecting comparable companies on the basis of functioning in the same branch and having concurrent activities. The comparative analysis comprised 47 companies dealing with power distribution. The set comprises one company originating in the United States of America and 46 European companies, 35 of which come from the European Community. The analysis includes 3 majority distribution companies acting in the Czech Republic: ČEZ Distribuce, a. s., E.ON Distribuce a. s., and Pražská energetika a. s.

\subsection{Criteria selection}

Both the CCR model and the Modified Score Method enable criteria to be selected. Due to this common character, the same criteria could be assessed for the CCR model and for the Modified Score Method. The following table contains the set of selected criteria.

Table 1: Valuation criteria for investment efficiency

\begin{tabular}{|c|}
\hline Inputs (minimization criteria) \\
\hline$x_{1}=\frac{\text { Investmens [mil. CZK] }}{\text { Assets [mil. CZK] }}$ \\
\hline$x_{2}=\frac{\text { Investmens [mil. CZK] }}{\text { Grid extended lenght [mil. CZK] }}$ \\
\hline$x_{3}=\frac{\text { Operating expenses [mil. CZK] }}{\text { Electricity distribution [GWh] }}$ \\
\hline$x_{4}=\frac{\text { Electricity losses [GWh] }}{\text { Electricity distribution [GWh] }}$ \\
\hline$y_{1}=\frac{\text { Operating profit [GWh] }}{\text { Investmens [mil. CZK] }}=x_{5}$ \\
\hline$y_{2}=\frac{\text { Electricity distribution [GWh] }}{\text { Investmens [mil. CZK] }}=x_{6}$ \\
\hline$y_{3}=\frac{\text { Number of connection [-] }}{\text { Assets [mil. CZK] }}=x_{7}$ \\
\hline
\end{tabular}

Table 1 shows the use of financial and non-financial indicators. This selection aims to raise the credibility of the valuation, which can be distorted when financial indicatorsare used, due to incompatible accounting practices Sưvová a kol. [4]. Since basic models of Data Analysis Envelopment require value comparability of the selected inputs and outputs, absolute indicator units are applied. These express the numerator or denominator of the selected criteria. However, it should be noted that the values of these absolute indicators were assessed as arithmetical averages of the values for the period 2003-2005. All data needed for evaluating the selected criteria were ascertained from the annual reports of the companies. 
Primary models are rarely found in applications of Data Analysis Envelopment models. Dual models are frequently used, because they contain a smaller number of constraints as well as additional variables that correct the calculation. This study therefore uses the dual CCR model, which is defined, e.g., in Dlouhý, Jablonský [5]. Due to the use of the Charnes-Cooper transformation and relatively low input and output values, infinitesimal constant $\varepsilon$ was set to a value of $10^{-3}$. For the solution exercises, the CCR model was created in MS Excel containing the Solver tool. The weights applied in the Modified Score Method are equal, due to the difficulty, is deciding which are more important.

\section{Conclusions}

The Modified Score Method and the CCR model of Data Analysis Envelopment were used to obtain the results presented in Appendix I of this paper. The companies receive an assessment in the range from 0 until 1 , where the best result is 1. The results of the CCR model show, that eight companies achieve the best valuation. The efficiency line is set by the following companies: EGL, Eidsiva Energinett, Electrabel, Hafslund Nett, Latvenergo, Statkraft, Vattenfall and Verbund. The least favorable valuation of the CCR model is given to ESB. The Modified Score Method selects Hafslund Nett as the best of all. Hafslund Nettis is also in the group of the best rated companies by the CCR model. The least favorable valuation on the basis of the Modified Score Method was given to Nuon. The arithmetical average of relative valuation Modified Score Method is 0.695, while in CCR model the average value is 0.535 .

A comparison of the results of the two methods on the basis of a relative valuation shows that there are considerable differences. For lucidity and for the purposes of analysis it is more suitable to put the companies into an order within the appropriate method. Appendix II of this paper is a graph that illustrates the results of both methods in terms of the achieved order. It should be emphasized that the more favorable the relative valuation is, the lower the position of the company in the ranking order. In order to compare the results of methods based on an assessment order it was necessary to use a so-called associated order, which uses the arithmetical mean of the order numbers. This means that the companies that occupy the same position are placed in an associated order. All eight best-assessed companies according to the CCR model are given a score of 4.5, since $(1+2+3+4+5+6+7+8) / 8$ give this order value. A comparison of the results introduced here shows that the two methods provide valuations that are not very significantly different, because most of the companies that are differently ordered are low in both rankings.
When assessing results presented here, it is necessary to note a potential threat to the companies that have achieved a favorable valuation. This result could be due e.g., to an unreasonably low level of investment in a given period, which can reduce the competitive advantage of that company in the future. The best situation is if a company has slightly above-average values of investment efficiency. When this average value is included in the total assessment order list, we find, that the average relative valuation using the Modified Score Method is 22nd. position (blue line in the figure presented in Appendix II), while the average relative valuation in the CCR model is 23rd. position (red line in figure presented in Appendix II).

As far as distribution companies operating in the Czech Republic are concerned, the figure in Appendix II shows, that these companies are placed, slightly above the average, for both methods. We can therefore consider the investment efficiency of most distribution companies operating in the Czech Republic to be satisfactory.

\section{Acknowledgments}

The author would like to express has gratitude to his supervisor, Prof. Ing. Oldřich Starý, CSc. for valuable comments and contributions.

\section{References}

[1] Dudorkin, J.: Systémové inženýrství a rozhodování. ČVUT, Praha, 2003.

[2] Fiala, P.: Modely a metody rozhodování. Oeconomia, Praha, 2003.

[3] Charnes, A., Cooper, W. W., Rhodes, E.: Measuring the Efficiency of Decision Making Units. European Journal of Operational Research, 1978a, p. 429-444.

[4] Sůvová, H. a kol.: Finanční analýza v ř́zení podniku, v bance a na počítači. Bankovní institut, Praha, 2000.

[5] Dlouhý, M., Jablonský, J.: Modely hodnocení efektivnosti produkčnich jednotek. Professional Publishing, Praha, 2004.

\section{Ing. Mirza Karajica}

karajm1@fel.cvut.cz

Dept. of Economics, Management and Humanities

Czech Technical University in Prague

Faculty Electrical Engineering,

Technická 2

16627 Praha, Czech Republic 


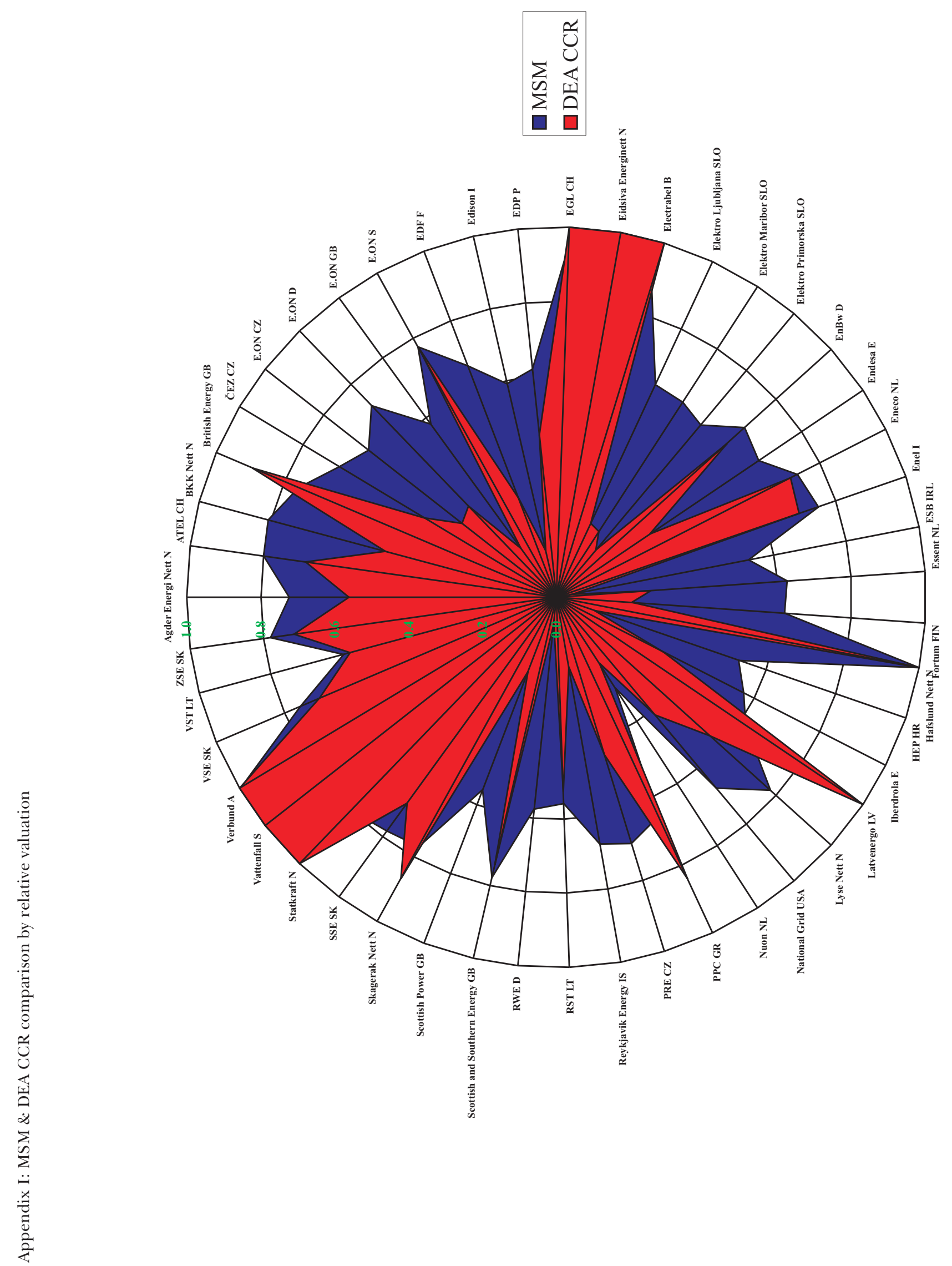




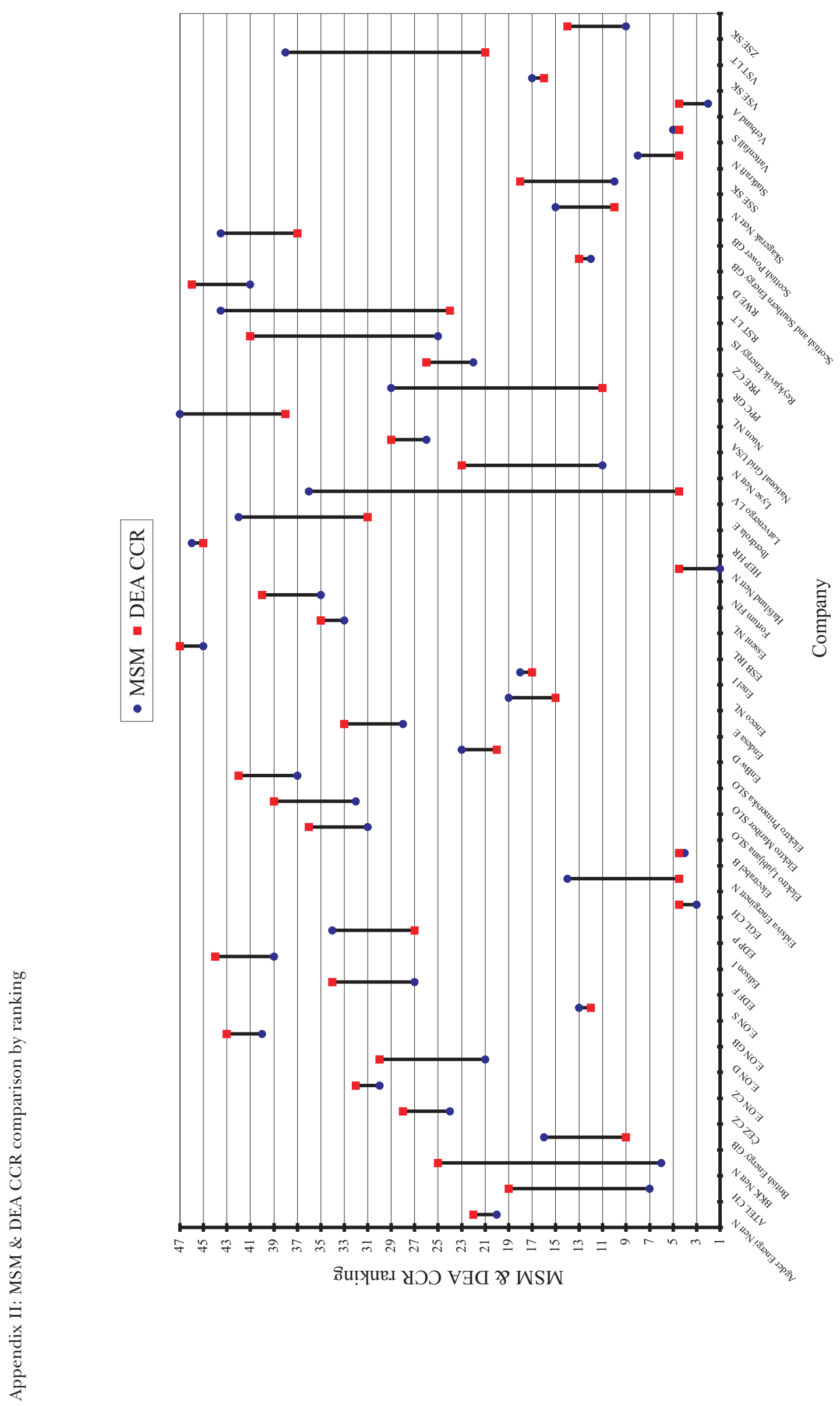

